\title{
Pemanfaatan Limbah Udang (Kitosan) Sebagai Koagulan Alami Dalam Penurunan Parameter Air Gambut
}

\author{
Siti Umi Kalsum ${ }^{1 *}$ dan Indro ${ }^{2}$ \\ ${ }^{1,2}$ Program Studi Teknik Lingkungan Universitas Batanghari \\ Jalan Slamet Riyadi, Broni, Kota Jambi \\ *email: siti.uk0616@gmail.com
}

\begin{abstract}
Rantau Karya Village is a coastal area of Tanjung Jabung Timur with a shallow peat depth of 1-2 meters and a medium depth of 3-4 meters that has peat water as a source of community life water and has potential marine resources such as shrimp. Shrimp waste that is not utilized by the community, as absorbance material in peat water treatment. This research conducted an experiment utilizing shrimp waste which, was transformed into chitosan as a natural coagulant in the process of peat water treatment. The method used is an experimental method and laboratory scale. The purpose of this study is to utilize shrimp waste into chitosan as a natural coagulant in reducing peat water parameter values and determining the optimum dose of chitosan in reducing peat water concentration. The results showed that chitosan shrimp waste could be used as a natural coagulant in the process of peat water treatment by raising the pH parameter values in peat water, reducing the color, iron, manganese, organic substances. The optimum dose obtained was a pH parameter of $400 \mathrm{mg} / \mathrm{l}$ with a percentage increase of $75 \%$, color $100 \mathrm{mg}$ $/ \mathrm{l}$ with a decrease of $49.52 \%$, iron $500 \mathrm{mg} / \mathrm{l}$ percentage of $85.44 \%$, manganese $100 \mathrm{mg} / \mathrm{l} 49.52 \%$ and organic matter $100 \mathrm{mg} / \mathrm{l}$ percentage $73.49 \%$.
\end{abstract}

Keywords: Chitosan; Natural coagulant; Peat Water; Rantau Karya Village

\section{Pendahuluan}

Air gambut merupakan air permukaan yang banyak dijumpai di daerah rawa, pesisir maupun dataran rendah terutama di Sumatera dan Kalimantan serta Papua yang memiliki karakteristik kandungan bahan organik yang tinggi, derajat keasaman yang rendah, besi dan warna yang tinggi (Said, dkk, 2008; Kusnadi, 2010). Karakteristik air gambut bersifat spesifik, tergantung pada lokasi, jenis vegetasi dan jenis tanah tempat air gambut tersebut berada, ketebalan gambut, usia gambut, dan cuaca.

Desa Rantau Karya Tanjung Jabung Timur Provinsi Jambi yang berada di dataran dengan ketinggian antara 6-10 meter di atas permukaan laut, jenis tanah berupa gambut dengan kedalaman dangkal 1-2 meter dan sampai sedang 3-4 meter. Lahan gambut ini tersebar di lahan usaha pertanian dan pemukiman penduduk. Dari luas lahan \pm 73.780 ha diperkirakan lahan yang tidak bergambut hanya $30 \%$ dan berada disekitar wilayah Pusat Pemerintahan Kabupaten Tanjung Jabung Timur. Berdasarkan analisa kesesuaian lahan, lahan bergambut yang kemiringannya $<8 \%$ dapat dikembangkan tanaman pangan, sedangkan untuk lahan yang kemiringannya $>8-25 \%$ untuk tanaman perkebunan.

Desa ini juga memiliki potensi sumber daya alam berupa udang. udang salah satu penghasil devisa sebagai komoditi ekspor, udang diolah dengan membuang bagian kepala, ekor, kaki dan kulit. Hasil buangan itu disebut limbah udang. limbah udang ini mengandung senyawa kitin. Kitin ditranspormasi menjadi kitosan. Kitosan ini dapat dijadikan sebagai koagulan alami untuk menurunkan parameter air gambut. Air gambut digunakan sebagai air bersih jika kualitas air memenuhi standar baku mutu yang ditetapkan dalam Permenkes 416 Tahun 1990.

Tujuan penelitian ini memanfaatkan limbah udang menjadi kitosan sebagai koagulan alami dalam menurunkan nilai parameter air gambut dan menentukan dosis optimum kitosan dalam menurunkan konsentrasi air gambut.

\section{Metode Penelitian}

\subsection{Lokasi penelitian}

Lokasi pengambilan sampel air baku dilakukan di Desa Rantau Karya Tanjung Jabung Timur Provinsi Jambi. Lokasi disajikan pada Gambar 1. Sedangkan untuk percobaan eksperimen dilakukan di Laboratorium Lingkungan Universitas Batanghari.

\subsection{Metode penelitian}

Metode dalam penelitian ini adalah metode eksperimen yaitu metode penelitian yang digunakan untuk mencari pengaruh perlakuan tertentu terhadap yang lain dalam kondisi yang terkendalikan (Sugiyono 2011:72).

Tahapan eksperimen pemanfaatan limbah udang (kitosan) untuk menurunkan konsentrasi air gambut terdiri dari: 1. pembersihan limbah udang yang diperoleh dari sumber limbah dengan mencuci; 2. Pengeringan dilakukan secara alami dengan panas matahari selama \pm 2 hari sampai kering; 3 . pengayakan/penghalusan menggunakan blender dan disaring dengan saringan ukuran 200 mesh menjadi bubuk koagulan; 4 . Penentuan dosis bubuk koagulan alami yaitu $100 \mathrm{mg}, 200 \mathrm{mg}$, $400 \mathrm{mg}, 500 \mathrm{mg}$; selanjutnya dilarutkan dengan aquades 100 $\mathrm{ml}$; 5. pengadukan larutan koagulan alami dengan air gambut volume $250 \mathrm{ml}$ dan variasi dosis yang telah ditentukan menggunakan Jartest variasi kecepatan pengadukan $160 \mathrm{rpm}$ dengan waktu 2 menit, $40 \mathrm{rpm}$ selama 10 menit selanjutnya larutan didiamkan selama 4 jam; 6. Setelah pengadukan akan tebentuk flok-flok suspensi dari air gambut; 7. Setelah itu diujikan hasilnya ke laboratorium.

Hasil uji laboratorium diinput dan dianalisis metode statistik menggunakan mikrosoft excel. Dari hasil analisis akan diperoleh dosis optimum dalam menurunkan konsentrasi parameter air gambut yaitu $\mathrm{pH}$, warna, besi, mangan, zat organik. Dari hasil eksperimen ini akan diperoleh dosis optimum untuk masing-masing parameter. 


\section{Hasil dan Pembahasan}

Hasil penelitian dari pemaafaatan kitosan untuk menurunkan nilai parameter dalam air gambut disajikan pada Tabel dan Grafik.

\subsection{Hasil uji air baku}

Uji sampel air baku air gambut diambil dari Desa Rantau Karya yang merupakan daerah pesisir di Kabupaten Tanjung Jabung Timur Provinsi Jambi yang disajikan pada Tabel 1.

Tabel 1. Hasil uji sampel air baku

\begin{tabular}{|c|c|c|c|c|}
\hline No. & $\underline{\text { Parameter }}$ & $\underline{\text { Satuan }}$ & $\frac{\text { Hasil Uji }}{\underline{(\mathrm{mg} / \mathrm{l})}}$ & $\begin{array}{c}\text { Baku } \\
\text { Mutu* }\end{array}$ \\
\hline 1 & $\mathrm{pH}$ & $=$ & $\underline{4}$ & $\begin{array}{l}6.5- \\
8.5\end{array}$ \\
\hline 2 & Warna & $\mathrm{PtCo}$ & 4.18 & 50 \\
\hline 3 & Besi (Fe) & $\mathrm{Mh} / 1$ & 2.37 & 1 \\
\hline 4 & Mangan (Mn) & $\mathrm{Mg} / \mathrm{l}$ & 0.024 & 0.5 \\
\hline 5 & $\begin{array}{l}\text { Zat Organic } \\
\text { (KMnO4) }\end{array}$ & $\mathrm{Mg} / \mathrm{l}$ & 562 & 10 \\
\hline
\end{tabular}

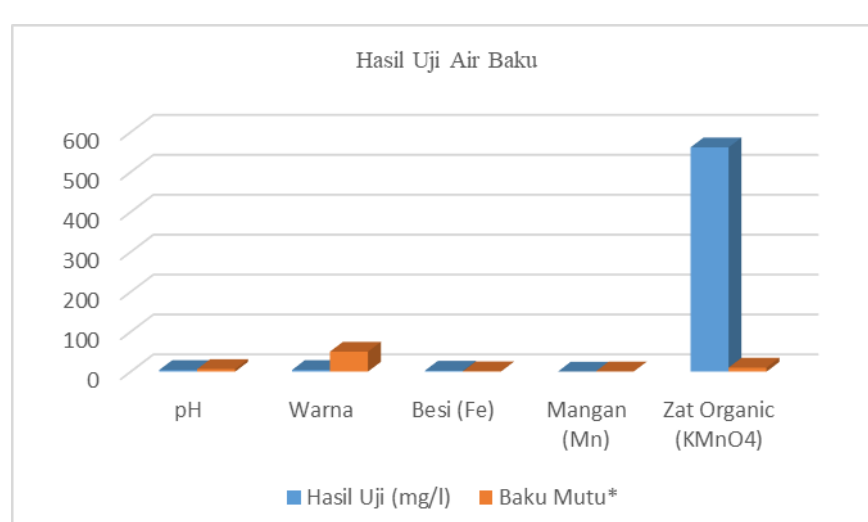

Gambar 1. Hasil uji air gambut (air baku)

\subsection{Hasil uji air olahan}

Hasil uji air gambut yang telah dilakukan eksperimen menggunakan koagulan alami dari kitosan dengan berbagai variasi dosis untuk menurunkan nilai konsentrasi parameter $\mathrm{pH}$, besi, mangan, warna dan zat organik disajikan pada Tabel dan Grafik 2 sampai 6.

Tabel 2. Hasil uji paramater $\mathrm{pH}$

\begin{tabular}{ccccc}
\hline No & $\begin{array}{c}\text { Variasi dosis koagulan } \\
(\mathrm{mg} / \mathrm{l})\end{array}$ & $\begin{array}{c}\text { Air } \\
\text { Baku }\end{array}$ & $\begin{array}{c}\text { Hasil } \\
\text { Uji }\end{array}$ & $\begin{array}{c}\text { Baku } \\
\text { Mutu* }\end{array}$ \\
\hline 1 & 100 & 4 & 5 & $6.5-8.5$ \\
2 & 200 & 4 & 6 & $6.5-8.6$ \\
3 & 400 & 4 & 7 & $6.5-8.7$ \\
4 & 500 & 4 & 7 & $6.5-8.8$ \\
\hline
\end{tabular}

*Permenkes Nomor 416/MenKes/Per/IX/1990

Tabel 3.Hasil uji parameter warna

\begin{tabular}{ccccc}
\hline & $\begin{array}{c}\text { Variasi dosis } \\
\text { No }\end{array}$ & & & \\
koagulan $(\mathrm{mg} / \mathrm{l})$ & Air Baku & Hasil Uji & Baku Mutu* \\
\hline 1 & 100 & 4.18 & 2.11 & 50 \\
2 & 200 & 4.18 & 3.51 & 50 \\
3 & 400 & 4.18 & 9.13 & 50 \\
4 & 500 & 4.18 & 2.14 & 50 \\
\hline
\end{tabular}

Tabel 4. Hasil uji parameter besi

\begin{tabular}{ccccc}
\hline No & $\begin{array}{c}\text { Variasi dosis } \\
\text { koagulan }(\mathrm{mg} / \mathrm{l})\end{array}$ & Air Baku & Hasil Uji & Baku Mutu* \\
\hline 1 & 100 & 2.37 & 0.098 & 1 \\
2 & 200 & 2.37 & 0.057 & 1 \\
3 & 400 & 2.37 & 0.463 & 1 \\
4 & 500 & 2.37 & 0.345 & 1 \\
\hline
\end{tabular}

Tabel 5. Hasil uji parameter mangan

\begin{tabular}{ccccc}
\hline & $\begin{array}{c}\text { Variasi dosis } \\
\text { No }\end{array}$ & & & \\
& koagulan $(\mathrm{mg} / \mathrm{l})$ & Air Baku & Hasil Uji & Baku Mutu* \\
\hline 1 & 100 & 0.024 & 0.049 & 0.5 \\
3 & 200 & 0.024 & 0.052 & 0.5 \\
4 & 400 & 0.024 & 0.057 & 0.5 \\
\hline
\end{tabular}

Tabel 6. Hasil uji parameter zat organik

\begin{tabular}{ccccc}
\hline No & $\begin{array}{c}\text { Variasi dosis } \\
\text { koagulan }(\mathrm{mg} / \mathrm{l})\end{array}$ & Air Baku & Hasil Uji & Baku Mutu* \\
\hline 1 & 100 & 562 & 149 & 10 \\
2 & 200 & 562 & 291 & 10 \\
3 & 400 & 562 & 449 & 10 \\
4 & 500 & 562 & 411 & 10 \\
\hline
\end{tabular}

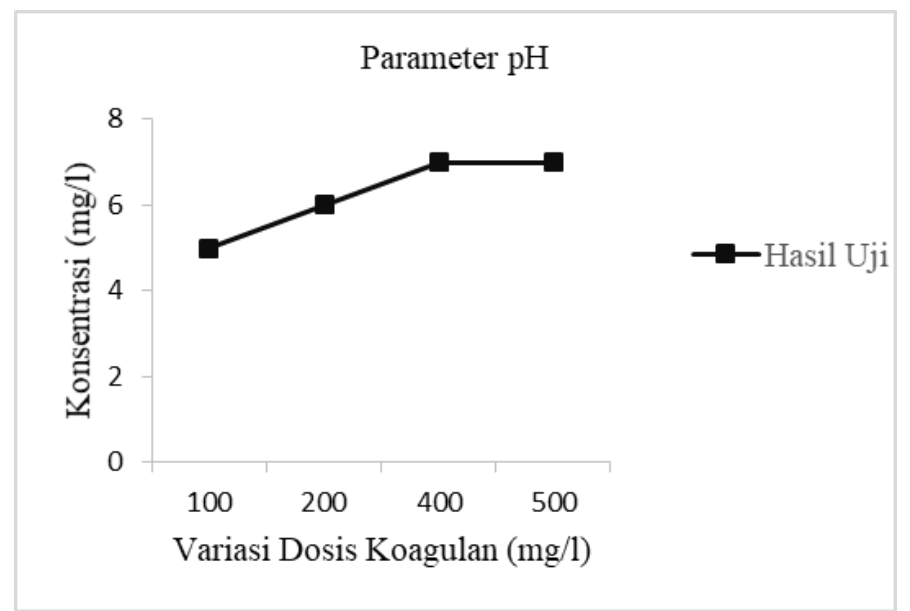

Gambar 2. Grafik hasil uji parameter $\mathrm{pH}$

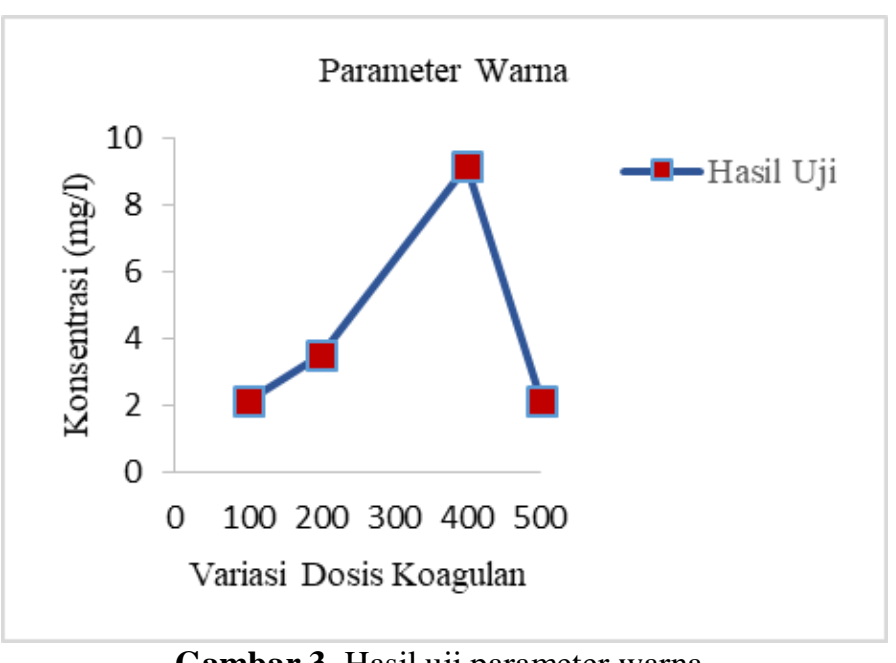

Gambar 3. Hasil uji parameter warna 


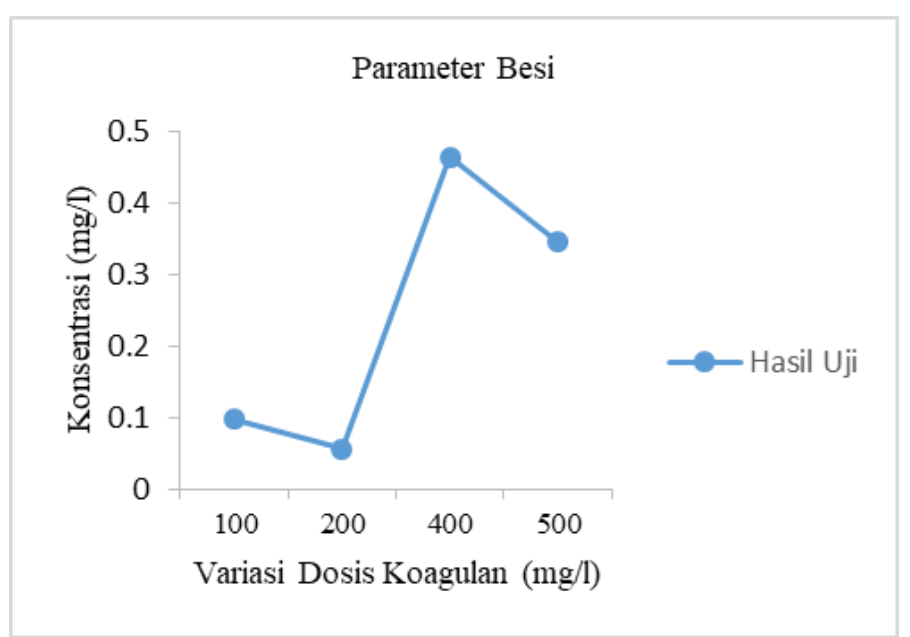

Gambar 4. Hasil uji parameter besi

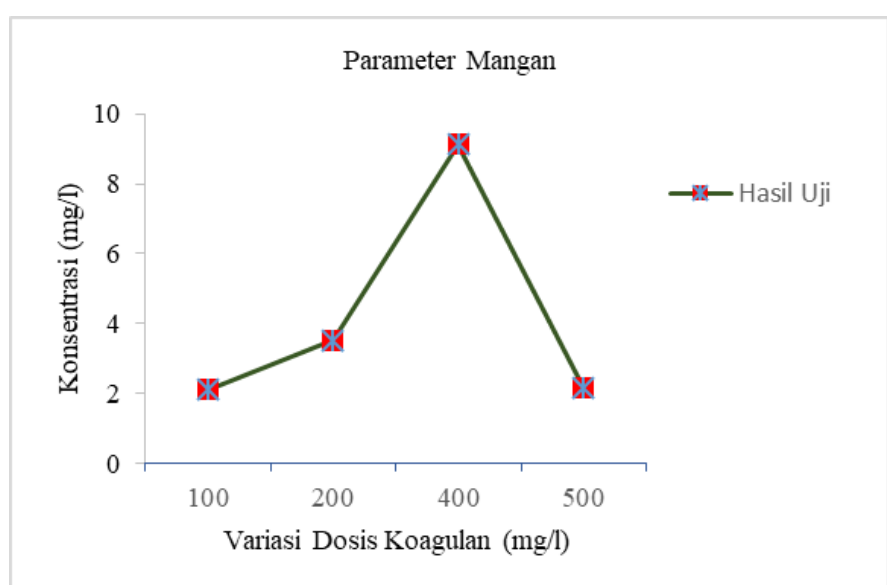

Gambar 5. Hasil uji parameter mangan

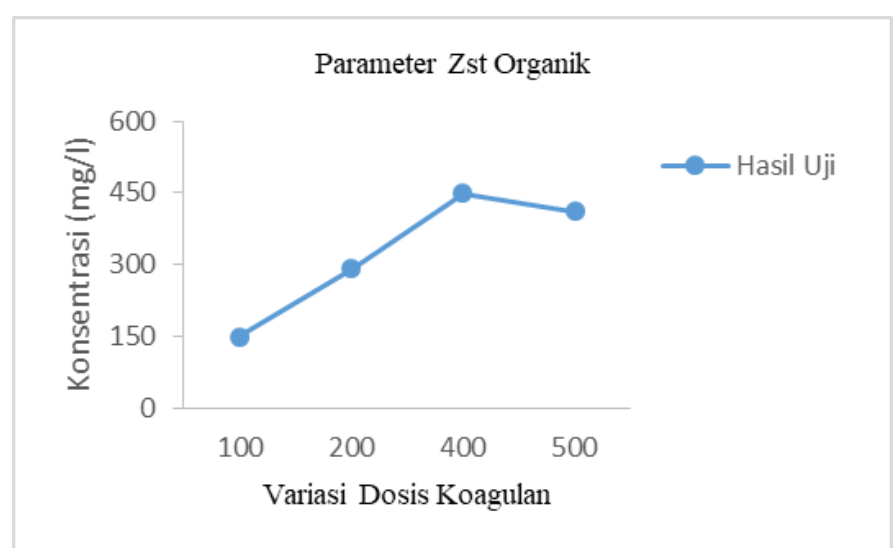

Gambar 6. Hasil uji parameter zat organik

Dari Tabel dan Grafik diatas menunjukkan bahwa untuk parameter $\mathrm{pH}$ mengalami kenaikan dari semula 4 menjadi 5 (dosis $100 \mathrm{mg} / \mathrm{l}), 5$ (dosis $200 \mathrm{mg} / \mathrm{l}), 7$ (dosis 400 $\mathrm{mg} / \mathrm{l}$ ), 7 (dosis $500 \mathrm{mg} / \mathrm{l}$ ), artinya kitosan ini mampu menaikan $\mathrm{pH}$ pada air gambut dengan persentase kenaikan sebesar $25 \%, 50 \%, 75 \%, 75 \%$. Dengan demikian dosis optimum koagulan alami kitosan dalam menurunkan parameter $\mathrm{pH}$ adalah dosis $400 \mathrm{mg} / \mathrm{l}$ dan menunjukkan bahwa semakin tinggi dosis koagulan, maka kenaikan $\mathrm{pH}$ akan lebih efektif. Selanjutnya untuk parameter warna mengalami penurunan dan kenaikan konsentrasi dari semula $4.18 \mathrm{mg} / \mathrm{l}$ menjadi $2,11 \mathrm{mg} / \mathrm{l}$, $3,51 \mathrm{mg} / \mathrm{l}, 9,13 \mathrm{mg} / \mathrm{l}$ dan 2,14. Kenaikan konsentrasi menjadi 9,13 pada dosis $400 \mathrm{mg} / \mathrm{l}$ menyatakan bahwa terjadi error pengujian eksperimen. Dosis optimum untuk paramater warna adalah $100 \mathrm{mg} / \mathrm{l}$ dengan penurunan sebesar 49,52 \%. Parameter besi air baku air gambut $2,37 \mathrm{mg} / 1$ menjadi 0,098 $\mathrm{mg} / \mathrm{l}, 0,057 \mathrm{mg} / \mathrm{l}, 0,463 \mathrm{mg} / \mathrm{l}, 0,345 \mathrm{mg} / \mathrm{l}$. dosis yang optimum adalah $500 \mathrm{mg} / \mathrm{l}$ artinya semakin tinggi dosis koagulan alami kitosan ini, maka semakin tinggi tingkat penurunan nilai konsentrasi untuk parameter besi sebesar $85,44 \%$. Untuk paramater mangan dengan nilai konsentrasi air baku 0,024 $\mathrm{mg} / \mathrm{l}$ mengalami penurunan konsentrasi menjadi $0,049 \mathrm{mg} / \mathrm{l}$, 0,052 mg/l, 0,057 mg/l, 0,029 mg/l. penurunan optimum pada dosis $100 \mathrm{mg} / \mathrm{l}$ artinya semakin rendah dosis koagulannya, maka semakin efektif dalam menurunkan nilai konsentrasi parameter mangan dengan persentase penurunan sebesar 49,52 $\%$. Parameter zat organik yang merupakan nilai konsentrasi tertinggi dari parameter lain yaitu sebesar $562 \mathrm{mg} / \mathrm{l}$ setelah dilakukan eksperimen mengalami penurunan sebesar 149 $\mathrm{mg} / \mathrm{l}, 291 \mathrm{mg} / \mathrm{l}, 449 \mathrm{mg} / \mathrm{l}, 411 \mathrm{mg} / \mathrm{l}$ dengan dosis optimum 100 $\mathrm{mg} / \mathrm{l}$ dan persentase penurunan sebesar $73,49 \%$ artinya semakin rendah dosis yang diberikan, maka semakin efektif dalam menurunkan parameter zat organik dalam air gambut.

Dari hasil penelitian ini menunjukkan bahwa kedalaman gambut menentukan nilai kandungan dan konsentrasi parameter yang ada di air gambut seperti zat organik,besi, mangan, warna dan derajat keasaman $(\mathrm{pH})$. Kedalaman gambut dangkal 1-2 meter dan kedalaman sedang memiliki kandungan parameter air yang berbeda. Untuk kandungan zat organik sangat tinggi, besi dan mangan rendah, $\mathrm{pH}$ asam, dan warna tidak pekat. Hal ini jika dilihat dari hasil uji air gambut dengan membandingkan dengan baku mutu air yang ditetapkan oleh pemerintah yaitu Permenkes 416 tahun 1990. Dan pemanfaatan limbah udang berupa kitosan dalam menurunkan kandungan nilai konsentrasi air pada air gambut memiliki keefektifan yang berbeda. Dalam memanfaatkan koagulan alami kitosan dalam menaikkan $\mathrm{pH}$ sangat efektif menggunakan dosis tinggi. Untuk parameter warna, mangan dan zat organik semakin rendah dosis koagulan yang digunakan, maka semakin efektif dalam menurunkan konsentrasi parameter air tersebut. Sedangkan untuk parameter besi membutuhkan dosis tinggi dalam menurunkan konsentrasi airnya.

Pemanafaatan koagulan alami telah dilakukan peneliti sebelumnya antara lain: Mawaddah, dkk, 2014,hasil penelitian air gambut dengan warna kecoklatan, $\mathrm{pH}$, bahan organik melalui proses koagulasi flokulasi menggunakan biji asam jawa. ditentukan berdasarkan nilai absorbansi UV pada panjang gelombang $254 \mathrm{~nm}$ dan bilangan permanganat. Pengamatan pengaruh $\mathrm{pH}$ larutan dan massa biji asam jawa terhadap penurunan bahan organik dilakukan dengan metode batch. Hasil penelitian menunjukkan bahwa penurunan bahan organik terbaik diperoleh pada hasil eksperimen dengan $\mathrm{pH} 4$ dan massa biji asam jawa sebanyak $2 \mathrm{~g}$ per $200 \mathrm{~mL}$ air gambut dengan perbandingan 1:1. Kondisi optimum ini mampu menurunkan bahan organik air gambut mencapai 50\%. Berdasarkan hasil penelitian disimpulkan bahwa biji asam jawa dapat digunakan sebagai koagulan dalam menurunkan bahan organik air gambut.

Rosyidah menunjukkan bahwa pemberian serbuk biji asam jawa (Tamarindus indica) berpengaruh terhadap kualitas air yang ditinjau dari aspek fisik, kimia, dan bakteriologi. Berdasarkan hasil penelitian, perlakuan terbaik diperoleh pada penambahan dosis serbuk biji asam jawa (Tamarindus indica) sebesar 1,0 g/L yang mampu menetralkan $\mathrm{pH}$ sebesar 7,02. Nilai dari parameter yang memenuhi baku mutu kualitas air kelas A pada parameter TSS, DO, dan pH. Sedangkan pada parameter BOD yang memenuhi kualitas air kelas A pada 
dosis $0,0 \mathrm{~g} / \mathrm{L}$ (kontrol) dan $1,0 \mathrm{~g} / \mathrm{L}$. Pada parameter COD yang memenuhi standar kualitas air kelas A terdapat pada dosis 0,0 $\mathrm{g} / \mathrm{L} ; 1,0 \mathrm{~g} / \mathrm{L} ;$ dan 1,4 g/L. Pada parameter bakteriologi (coliform) dosis 1,4 g/L mampu menurunkan jumlah bakteri dan memenuhi standar baku mutu kualitas air kelas A.

Biji asam jawa (Tamarindus indica) sebagai koagulan alami alternatif pada pengolahan air gambut dapat menurunkan kadar parameter warna sebesar $65,75 \%$ pada berat koagulan 4 gram, parameter besi $(\mathrm{Fe})$ 84,09\% pada berat koagulan 4 gram, zat organik $80,82 \%$ pada berat koagulan 4 gram (Maya Riskita, 2014).

\section{Kesimpulan}

Dari hasil eksperimen dan analisis pemanfaatan koagulan alami kitosan dalam menurunkan parameter air gambut dan analisis diatas dapat disimpulkan sebagai berikut:

Limbah udang kitosan dapat dimanfaatkan sebagai koagulan alami pengganti koagulan kimia pada air gambut yang dapat menaikan nilai parameter $\mathrm{pH}$ pada air gambut, menurunkan parameter warna, besi, mangan dan zat organik.

Dosis optimum masing-masing parameter yang diperoleh dari penelitian pemanfaatan limbah udang kitosan ini adalah parameter $\mathrm{pH} 400 \mathrm{mg} / \mathrm{l}$ dengan persentase kenaikan $75 \%$, warna $100 \mathrm{mg} / \mathrm{l}$ dengan persentase penurunan $49,52 \%$,

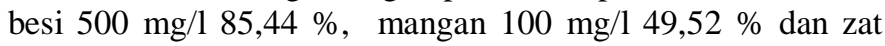
organik mengalami penurunan pada $100 \mathrm{mg} / \mathrm{l}$ dengan persentase $73,49 \%$.

\section{Daftar Pustaka}

Kusnaidi, (2010). Mengolah Air Kotor Untuk Air Minum.Jakarta.

Menteri Kesehatan, (1990). Peraturan Menteri Kesehatan Republik Indonesia Nomor 416/MENKES/PER/IX/1990 Tentang Syarat-Syarat Pengawasan Kualitas Air.

Mawaddah, dkk. (2014). Penurunan bahan organik air gambut menggunakan biji asam jawa. Jurnal Jkk Volume 3(1).Hal27-31.

Maya Riskita, (2014). Tugas Akhir. Pemanfaatan serbuk biji asam jawa sebagai kooagulan untuk pengolahan air gambut desa Teluk dawan tanjung jabung timur

Rosyidah, (2008). Skipsi, Uji Dosis Serbuk Biji Asam Jawa (Tamarindus Indica) Sebagai Biokoagulan t0erhadap Kualitas Air Ditinjau Dari Aspek Fisik, Kimia, Dan Bakteriologi.UI Malang.

Ramadhani. dkk, (2013). Pemanfaatan Biji Asam Jawa (Tamarindusindica) Sebagai Koagulan Alternatif Dalam Proses Menurunkan Kadar Cod Dan Bod Dengan Studi Kasus Pada Limbah Cair Industri Tempe. (Its). Jurnal Teknik Pomits Vol. 2, No. 1, (2013) Issn: 2337-3539 (2301-9271).

Said, (2008). Teknologi Pengolahan Air Minum. (Teori dan Pengalaman Praktis) Bab 8. Badan Pengkajian Dan Penerapan Teknologi. Jakarta.

Sugiyono. (2011). Metode Penelitian Kuantitatif Kualitatif dan R\&D. Bandung: Alfabeta. 